\title{
Influence of sex and gonadal status of sheep on cortisol secretion in response to ACTH and on cortisol and LH secretion in response to stress: importance of different stressors
}

\author{
A I Turner, B J Canny, R J Hobbs, J D Bond, I J Clarke ${ }^{1}$ \\ and A J Tilbrook \\ Department of Physiology, PO Box 13F, Monash University, VIC 3800, Australia \\ ${ }^{1}$ Prince Henry's Institute of Medical Research, Clayton, VIC 3168, Australia \\ (Requests for offprints should be addressed to A I Turner; Email: anne.turner@med.monash.edu.au)
}

\begin{abstract}
There are sex differences in the response to stress and in the influence of stress on reproduction which may be due to gonadal steroids but the nature of these differences and the role of the gonads are not understood. We tested the hypotheses that sex and the presence/absence of gonads (gonadal status) will influence the cortisol response to injection of ACTH, insulin-induced hypoglycaemia and isolation/restraint stress, and that sex and gonadal status will influence the secretion of $\mathrm{LH}$ in response to isolation/ restraint stress. Four groups of sheep were used in each of three experiments: gonad-intact rams, gonadectomised rams, gonad-intact ewes in the mid-luteal phase of the oestrous cycle and gonadectomised ewes. In Experiment 1 ( $n=4$ /group), jugular blood samples were collected every $10 \mathrm{~min}$ for $6 \mathrm{~h}$; after $3 \mathrm{~h}$, two animals in each group were injected (i.v.) with ACTH and the remaining two animals were injected (i.v.) with saline. Treatments were reversed 5 days later so that every animal received both treatments. Experiment 2 ( $n=4$ /group) used a similar schedule except that insulin was injected (i.v.) instead of ACTH. In Experiment 3 ( $n=5 /$ group), blood samples were collected every $10 \mathrm{~min}$ for $16 \mathrm{~h}$ on a control day and again 2 weeks later when, after $8 \mathrm{~h}$ of sampling, all sheep were isolated
\end{abstract}

and restrained for $8 \mathrm{~h}$. Plasma cortisol was significantly $(P<0 \cdot 05)$ elevated following injection of ACTH or insulin and during isolation/restraint stress. There were no significant differences between the sexes in the cortisol response to ACTH. Rams had a greater $(P<0 \cdot 05)$ cortisol response to insulin-induced hypoglycaemia than ewes while ewes had a greater $(P<0 \cdot 05)$ cortisol response to isolation/restraint stress than rams. There was no effect of gonadal status on these parameters. Plasma LH was suppressed $(P<0.05)$ in gonadectomised animals during isolation/restraint stress but was not affected in gonadintact animals, and there were no differences between the sexes. Our results show that the sex that has the greater cortisol response to a stressor depends on the stressor imposed and that these sex differences are likely to be at the level of the hypothalamo-pituitary unit rather than at the adrenal gland. Since there was a sex difference in the cortisol response to isolation/restraint, the lack of a sex difference in the response of $\mathrm{LH}$ to this stress suggests that glucocorticoids are unlikely to be a major mediator of the stress-induced suppression of LH secretion.

Journal of Endocrinology (2002) 173, 113-122

\section{Introduction}

Stress can impair reproduction in many species (for reviews see Moberg 1987, Rivier \& Rivest 1991, Dobson \& Smith 1995, Tilbrook et al. 2000) but the mechanisms by which this occurs are not well understood (Tilbrook et al. 2000). A number of physiological pathways are activated by stress and the pathways that are activated can depend on the type of stressor encountered (Moberg 1985). Stress-induced activation of the hypothalamopituitary-adrenal axis differs between the sexes in a number of species and it is commonly accepted that sex steroids are largely responsible for these sex differences
(Handa et al. 1994, Da Silva 1995, Young 1995, Patchev \& Almeida 1998). For instance, in rats, both basal and stress-induced concentrations of glucocorticoids and the glucocorticoid response to standard treatment with adrenocorticotrophic hormone (ACTH) were greater in females than in males (Kitay 1961). In sheep, we have shown differences between the sexes in the activity of the hypothalamo-pituitary-adrenal axis in vitro (Canny et al. 1999). Males had higher concentrations of arginine vasopressin (AVP) in the median eminence, higher concentrations of pro-opiomelanocortin in the anterior pituitary gland and higher basal secretion of cortisol from cultured adrenal cells than females. In contrast, females had higher 
basal secretion of ACTH from cultured anterior pituitary cells, heavier adrenal glands and greater ACTH-induced production of cortisol from cultured adrenal cells than males (Canny et al. 1999). Despite these in vitro findings, we found no differences in the stress-induced secretion of cortisol in gonadectomised male and female sheep that were treated with various combinations of sex steroids (Tilbrook et al. 1999). Gonadectomised males were treated intramuscularly with oil or testosterone and gonadectomised females were treated with oil, oestradiol, progesterone or a combination of oestradiol and progesterone, and all animals were subjected to a stressor that consisted of isolation and restraint for $4 \mathrm{~h}$ (Tilbrook et al. 1999). These findings were not consistent with our earlier in vitro results in sheep or results in other species showing differences between the sexes in the activity of the hypothalamo-pituitary-adrenal axis (vide supra).

To elucidate fully whether there are sex differences in the activity of the hypothalamo-pituitary-adrenal axis in sheep, it is necessary to test for such differences in gonad-intact animals. This is critical because, in these animals, the secretion of gonadal hormones occurs in a physiological manner and because there may be nonsteroidal factors from the gonads that influence the hypothalamo-pituitary-adrenal axis. Furthermore, in order to compare the activity of the hypothalamopituitary-adrenal axis between the sexes, it is necessary to activate this axis using different stressors because different stressors activate different pathways (e.g. Rivier \& Rivest 1991) and/or different stressors may activate the same pathway differently. For instance, a metabolic stressor that has been shown consistently to activate the hypothalamopituitary-adrenal axis in sheep is insulin-induced hypoglycaemia (Engler et al. 1989, Canny et al. 1989, Caraty et al. 1990). On the other hand, a stressor that involves both psychological and physical components, and is known to activate the hypothalamo-pituitary-adrenal axis in sheep, is a treatment that combines isolation and restraint (Tilbrook et al. 1999). Moreover, injecting a standard amount of ACTH in rams and ewes can be used to assess whether sex differences exist in sheep in the activity of the adrenal cortex.

In addition to sex differences in the activity of the hypothalamo-pituitary-adrenal axis, it is also reasonable to suggest that the mechanisms by which stress impairs reproduction may differ between the sexes and that the sex steroids may influence these. This area has received little attention in any species. When we treated gonadectomised male and female sheep with combinations of sex steroids, we found that, while the secretion of $\mathrm{LH}$ was impaired in all animals during stress, the mechanism of suppression depended on the sex of the animal and which sex steroids were present (Tilbrook et al. 1999). Nevertheless, to elucidate fully sex differences in the impact of stress on reproduction, it is necessary to study gonad-intact animals where the secretion of gonadal hormones occurs in a physiological manner. Consequently, in the current study, we used gonad-intact and gonadectomised male and female sheep to test two hypotheses. Firstly, that sex and gonadal status influence the secretion of cortisol in response to injection of ACTH, insulin-induced hypoglycaemia and isolation/restraint stress and, secondly, that sex and gonadal status influence the secretion of LH in response to isolation/restraint stress.

\section{Materials and Methods}

\section{Animals}

Adult Romney Marsh rams and ewes were studied in three experiments at the Victorian Institute of Animal Science, Werribee, Australia (latitude $38^{\circ}$ south) during the transition from the breeding season to the nonbreeding season for this breed (Bremner et al. 1984). Groups of gonad-intact rams, gonadectomised rams, gonad-intact ewes in the mid-luteal phase of the oestrous cycle and gonadectomised ewes were used. The same sheep were used in Experiments 1 and 2. In Experiments 1 and 2, there were four animals in each group, gonadectomy was carried out 6 weeks prior to Experiment 1 and the live-weight of the animals ranged from 47-69 $\mathrm{kg}$ at the start of the experiments. For 4 weeks before experimentation, sheep in Experiments 1 and 2 were moved each day from pasture into a purpose-built experimental shed where they were housed individually, adjacent and opposite to pens containing the other sheep in the experiment. Every second day, to familiarise the sheep to a moderate level of handling, an experimenter approached and handled each of the sheep. In Experiment 3, there were five animals in each group but the catheter of one gonadectomised male did not remain patent leaving four animals in this group. These sheep were gonadectomised 12 months before experimentation and weighed $50-86 \mathrm{~kg}$ when the experiment started. To familiarise these sheep with the experimental set up, they were brought into the shed and housed in experimental pens for 2 weeks before the start of the experiment. Other than daily feeding, these sheep did not receive any specific contact with humans before experimentation began.

In each experiment, all sheep were given a maintenance ration of lucerne chaff and allowed free access to water. Two days before Experiments 1 and 2, and 1 day before Experiment 3, each animal was fitted with an indwelling jugular venous catheter (Dwellcath, Tuta Laboratories, Lane Cove, Australia) for the collection of blood samples.

To synchronise oestrous cycles of gonad-intact ewes in Experiments 1 and 2, intravaginal controlled internal drug release devices (CIDRs, Riverina Artificial Breeders Pty Ltd, Albury, NSW, Australia) containing $0 \cdot 3 \mathrm{~g}$ progesterone were inserted for 6-11 days commencing 13-21 days prior to experimental days. At the time of removal of CIDRs, ewes were injected (i.m.) with prostaglandin 
$(125 \mu \mathrm{g}$ Cloprostenol, Troy Laboratories Pty Ltd, Smithfield, NSW, Australia) (Parr et al. 1987). In Experiment 3, oestrous ewes were identified by housing intact ewes with a vasectomised ram fitted with a ram harness and crayon (Radford et al. 1960). Five oestrous ewes (with crayon marks) were selected and injected (i.m.) with prostaglandin (125 $\mu \mathrm{g}$ Cloprostenol, Troy Laboratories Pty Ltd, Smithfield, NSW, Australia). Confirmation that intact ewes were in the luteal phase of the oestrous cycle on experimental days was obtained by determining the plasma concentrations of progesterone in all females. In intact ewes, plasma concentrations of progesterone were $1 \cdot 8 \pm 0 \cdot 5,1 \cdot 0 \pm 0 \cdot 1$ and $1 \cdot 3 \pm 0 \cdot 2 \mathrm{ng} /$ $\mathrm{ml}$ and, in gonadectomised ewes, plasma concentrations of progesterone were $0 \cdot 1 \pm 0,0 \cdot 1 \pm 0$ and $0 \cdot 1 \pm 0 \cdot 1 \mathrm{ng} / \mathrm{ml}$ in Experiments 1,2 and 3, respectively. Values are expressed as means ( \pm S.E.M.) calculated from concentrations in three samples collected across the day. These concentrations are similar to those previously reported in intact ewes in the luteal and follicular phases of the oestrous cycle, respectively (Thorburn et al. 1969).

The care and experimental use of the animals in this experiment conformed to the requirements of the Australian Prevention of Cruelty to Animals Act 1986 and the NHMRC/CSIRO/AAC 'Australian code of practice for the care and use of animals for scientific purposes'. The Animal Ethics Committee of the Victorian Institute of Animal Science approved all of the procedures which involved animals in this investigation.

\section{Experimental procedure}

Experiment 1 - response to ACTH Blood samples $(5 \mathrm{ml})$ were collected every $10 \mathrm{~min}$ for $6 \mathrm{~h}$. After the first $3 \mathrm{~h}$, two sheep in each group were injected (i.v.) with ACTH $\left(0 \cdot 2 \mu \mathrm{g} \mathrm{ACTH}{ }_{1-24} / \mathrm{kg}\right.$ live-weight, Synacthen, Ciba-Geigy Australia Ltd, Thomastown, VIC, Australia). The remaining two sheep in each group were injected (i.v.) with an equivalent volume of saline $(2 \mathrm{ml})$. Five days later, this blood sampling procedure was repeated but the treatments were crossed over so that sheep that had previously received ACTH were administered saline and those that had previously received saline were administered ACTH. Concentrations of cortisol and $\mathrm{LH}$ were measured in plasma harvested from all blood samples.

The dose of ACTH was determined in a pilot study (AJ Tilbrook, BJ Canny \& JD Bond, unpublished) in which 0 , $0.02,0.2$ or $2.0 \mu \mathrm{g} \mathrm{ACTH} / \mathrm{kg}$ live-weight was administered (i.v.) to groups of gonadectomised rams $(n=4$ per group). Plasma concentrations of cortisol were determined in blood samples $(5 \mathrm{ml})$ collected every $15 \mathrm{~min}$ for $2 \mathrm{~h}$ before and 10, 20, 30, 45, 60, 75, 90, 105 and $120 \mathrm{~min}$ after injection of ACTH or saline. Based on the peak height of the cortisol response, injection of $0 \cdot 2 \mu \mathrm{g}$ $\mathrm{ACTH} / \mathrm{kg}$ live-weight was found to induce a maximal adrenal response (data not shown).

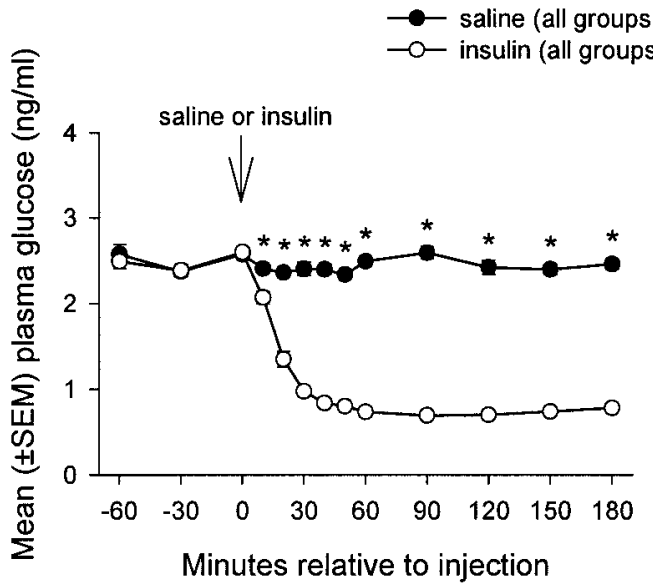

Figure 1 Mean ( \pm S.E.M.) plasma concentrations of glucose in all animals (gonad intact+gonadectomised males + females) for $60 \mathrm{~min}$ before to $180 \mathrm{~min}$ after intravenous injection of saline and insulin (2 IU/kg live-weight; $O)$. *Significant $(P<0 \cdot 05)$ difference between plasma glucose following treatment with saline and treatment with insulin.

Experiment 2 - response to insulin-induced hypoglycaemia Three weeks after the completion of Experiment 1, the procedures used to determine the 'Response to ACTH' were repeated using the same animals but, instead of injecting ACTH, hypoglycaemia was induced by injection (i.v.) of natural human insulin (2 $\mathrm{IU} / \mathrm{kg}$ live-weight, Actrapid, CSL-NOVO Pty Ltd, Parkville, VIC, Australia). Two sheep in each group were administered insulin while the remaining two sheep received saline (i.v.) and, after 3 days, the blood sampling procedure was repeated and the treatments were crossed over so that each sheep received each treatment. This dose of insulin was based on a previous study (Canny et al. 1989). Concentrations of cortisol were measured in plasma harvested from all blood samples. Plasma concentrations of glucose were measured in samples collected 60, 30 and 0 min before and 10, 20, 30, 40, 50, 60, 90, 120, 150 and $180 \mathrm{~min}$ after injection of insulin or saline using a glucose/ lactate analyser (2300 STAT Glucose/L-Lactate Analyzer, Yellow Springs Incorporated, Yellow Springs, OH, USA). Statistical analyses are described below. Plasma concentrations of glucose were significantly $(P<0 \cdot 05)$ lower at each time point following injection of insulin compared with those at the equivalent time on the day of injection of saline (Fig. 1). There were no significant differences between males and females or between gonad-intact and gonadectomised animals. Because of this, the data from animals in all groups were combined for presentation in Fig. 1.

Experiment 3 - response to isolation/restraint stress On the first day of the experiment, blood samples $(5 \mathrm{ml})$ were collected from all animals every $10 \mathrm{~min}$ for $16 \mathrm{~h}$. 
Two weeks later, blood samples were again collected every $10 \mathrm{~min}$ for $16 \mathrm{~h}$ but, on this occasion, all sheep were isolated and restrained for $8 \mathrm{~h}$ after the first $8 \mathrm{~h}$ of sampling. The isolation/restraint treatment has been described in detail previously and has been characterised in terms of activation of the hypothalamo-pituitary-adrenal axis and suppression of LH secretion (Tilbrook et al. 1999). Briefly, this treatment involved harnessing each animal to the side of a novel pen that was covered on all sides with hessian. The animal could move its head and drink water freely. Plasma concentrations of cortisol were measured for each animal in pools of plasma that represented each of the hours before treatment and hours 2-8 after treatment, and in every sample collected during the first hour of treatment. Plasma concentrations of LH were measured in all samples.

\section{Cortisol radioimmunoassay}

Total plasma concentrations of cortisol were measured, following extraction of plasma using dichloromethane, by a radioimmunoassay which has been described previously (Bocking et al. 1986) using cortisol (H-4001, Sigma Chemical Company, St Louis, MO, USA) as standard. In Experiments 1 and 2, the mean ( \pm S.E.M.) recovery of $\left[{ }^{3} \mathrm{H}\right]$ cortisol using this extraction procedure was $95 \pm 1 \%$. There were 34 assays conducted with a mean ( \pm S.E.M.) assay sensitivity of $0.7 \pm 0.1 \mathrm{ng} / \mathrm{ml}$. The intra-assay coefficient of variation was $14 \%$ at $68 \mathrm{ng} / \mathrm{ml}$ and the inter-assay coefficient of variation was $13 \%$ at $84 \mathrm{ng} / \mathrm{ml}$. In Experiment 3 , the mean ( \pm S.E.M.) recovery of $\left[{ }^{3} \mathrm{H}\right]$ cortisol using this extraction procedure was $96 \pm 1 \%$ and 18 assays were conducted with a mean ( \pm S.E.M. $)$ assay sensitivity of $0 \cdot 9 \pm 0 \cdot 1 \mathrm{ng} / \mathrm{ml}$. The intra-assay coefficient of variation was $10 \%$ at $7 \mathrm{ng} / \mathrm{ml}$ and the inter-assay coefficient of variation was $20 \%$ at $7 \mathrm{ng} / \mathrm{ml}$.

\section{$L H$ radioimmunoassay}

Plasma concentrations of $\mathrm{LH}$ were determined in Experiment 3 using a radioimmunoassay described by Lee et al. (1976) using NIH LH S18 as standard. Sixteen assays were conducted with a mean $( \pm$ S.E.M.) assay sensitivity of $0 \cdot 5 \pm 0 \cdot 1 \mathrm{ng} / \mathrm{ml}$. The intra-assay coefficient of variation was $13 \%$ at $3.5 \mathrm{ng} / \mathrm{ml}$ and the inter-assay coefficient of variation was $18 \%$ at $6 \cdot 3 \mathrm{ng} / \mathrm{ml}$.

\section{Progesterone radioimmunoassay}

Commercially available radioimmunoassay kits were used to measure plasma concentrations of progesterone in Experiments 1 and 2 (Coat-A-Count, Diagnostic Products Corporation, CA, USA) and in Experiment 3 (Prog-RIA-CT, BioSource, Europe S.A., Belgium). For Experiments 1 and 2, one assay was conducted with an assay sensitivity of $0.03 \mathrm{ng} / \mathrm{ml}$. The intra-assay coefficient of variation was $2 \cdot 6-6 \cdot 4 \%$. In Experiment 3, one assay was conducted with an assay sensitivity of $0.05 \mathrm{ng} / \mathrm{ml}$. The intra-assay coefficient of variation was $12 \%$ at $0.6 \mathrm{ng} / \mathrm{ml}$.

\section{Statistical analyses}

All values are given as means IS.E.M. Plasma concentrations of cortisol, glucose and the parameters of LH secretion (described below) were compared within and between subjects using repeated measures analysis of variance. The between subjects factors were sex and gonadal status and the within subjects factors were day and time. Where applicable, post hoc paired comparisons were carried out using least significant differences. Repeated measures analysis of variance was also used to analyse pretreatment plasma concentrations of cortisol. The between subjects factors were sex and gonadal status and the within subjects factor was day. For any parameter where the variance was not homogeneous, the data were transformed (square root) before statistical analysis was performed. This made the variance of the data homogeneous.

Pretreatment plasma concentrations of cortisol were calculated by taking the mean of concentrations $30-0 \mathrm{~min}$ before the injection of ACTH or saline (Experiment 1) or a mean of concentrations $50-0 \mathrm{~min}$ prior to injection of insulin or saline (Experiment 2). These samples were chosen because, across all groups and both days in Experiment 1, plasma from samples taken 30, 20, 10 and $0 \mathrm{~min}$ before injection of saline or ACTH $(11 \cdot 4 \pm 2 \cdot 6$, $10 \cdot 7 \pm 2 \cdot 1,9 \cdot 8 \pm 2 \cdot 1$ and $9 \cdot 5 \pm 2 \cdot 1 \mathrm{ng} / \mathrm{ml}$, respectively) had a significantly $(P<0 \cdot 01)$ lower concentration of cortisol than that from the first blood sample of the day $(20.1 \pm 3.7 \mathrm{ng} / \mathrm{ml})$. In Experiment 2, plasma concentrations of cortisol 50, 40, 30, 10 and 0 min before insulin or saline injection $(5 \cdot 8 \pm 0 \cdot 7, \quad 5 \cdot 2 \pm 0 \cdot 8, \quad 5 \cdot 7 \pm 0.9$, $5 \cdot 1 \pm 0.6$ and $5.9 \pm 0.6 \mathrm{ng} / \mathrm{ml}$, respectively) were found to be significantly $(P<0 \cdot 05)$ less than concentrations in the first sample of the day $(9 \cdot 7 \pm 1 \cdot 0 \mathrm{ng} / \mathrm{ml})$. The concentration of cortisol $20 \mathrm{~min}$ before insulin or saline injection $(6 \cdot 7 \pm 1 \cdot 0 \mathrm{ng} / \mathrm{ml})$ was not significantly different to that at the start of the day but, for completeness, values at this time were included in calculations of pretreatment concentrations. In Experiment 3, pretreatment plasma concentrations of cortisol were taken as the concentration in the pool of plasma that represented the hour prior to the onset of isolation/restraint stress or the equivalent time on the control day.

Pulses of LH were identified using the procedure described by Karsch et al. (1987). That is, a pulse was defined as an abrupt increase in the concentration of $\mathrm{LH}$ that was greater than assay sensitivity, exceeded the preceding value by at least 3 times its standard deviation and was followed by a progressive decline at a rate consistent with the reported half-life of LH in sheep of 29 min (Geschwind \& Dewey 1968). The parameters of 


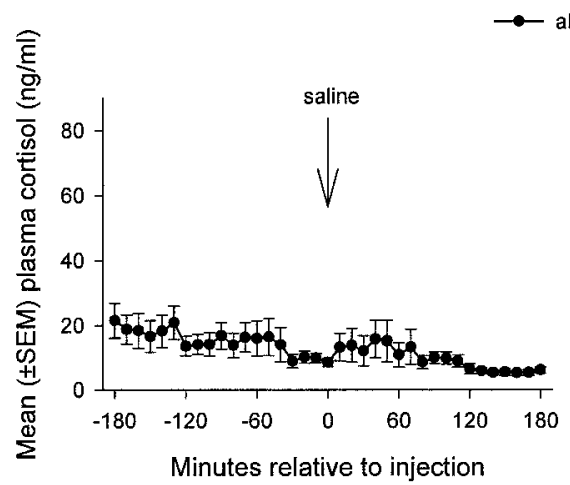

groups combined

Figure 2 Mean ( \pm S.E.M.) plasma concentrations of cortisol in all animals (gonad intact+gonadectomised males +females; - ) for $180 \mathrm{~min}$ before to $180 \mathrm{~min}$ after intravenous injection of saline (left panel) and ACTH $\left(0 \cdot 2 \mu \mathrm{gCTH}_{1-24} / \mathrm{kg}\right.$ live-weight; right panel). Significant changes over time are described in Results.

LH secretion investigated were mean concentrations, LH pulse amplitude, the number of pulses per hour and the pre-LH pulse nadir. For analysis of each LH parameter, the data from each day were divided into $4 \mathrm{~h}$ blocks (i.e. two before imposition of the isolation/restraint stress and two during the period of stress or during the equivalent times on the day of no stress). Mean LH concentrations were calculated using all values in a $4 \mathrm{~h}$ block. The amplitude of LH pluses was calculated as the difference between the peak and the preceding nadir. The number of pulses per hour was calculated as the total number of pulses in a $4 \mathrm{~h}$ block divided by 4 . Pre-LH pulse nadir was taken as the plasma LH concentration that preceded a pulse. If there were no pulses identified in a block, the mean plasma concentration of $\mathrm{LH}$ was used as the pre-LH pulse nadir.

\section{Results}

Experiment 1 - response to $A C T H$

Plasma concentrations of cortisol Overall (all groups combined), plasma concentrations of cortisol were significantly $(P<0 \cdot 01)$ higher than pre-treatment concentrations from 10-80 min after injection of ACTH (Fig. 2). In contrast, there were no significant changes in the plasma concentrations of cortisol in response to injection of saline (Fig. 2).

The increase in plasma concentrations of cortisol following injection of ACTH did not differ significantly between males and females or between gonad-intact and gonadectomised animals. For this reason, the data from all groups were combined for presentation in Fig. 2.

Pretreatment plasma concentrations of cortisol were significantly $(P<0 \cdot 05)$ higher in gonadectomised (males+ females) than in gonad-intact (males+females) animals (Table 1). Sex did not influence pretreatment concentrations of cortisol.

\section{Experiment 2 - response to insulin-induced hypoglycaemia}

Plasma concentrations of cortisol Overall (all groups combined), mean ( \pm S.E.M.) plasma concentrations of cortisol 10-30 min after injection of insulin did not differ significantly from pretreatment concentrations (Fig. 3). Nevertheless, concentrations $40 \mathrm{~min}$ after injection of insulin were significantly $(P<0 \cdot 05)$ greater than pretreatment concentrations and these levels continued to be significantly $(P<0 \cdot 05)$ greater than pretreatment

Table 1 Mean ( \pm S.E.M.) pretreatment plasma concentrations of cortisol $(\mathrm{ng} / \mathrm{ml})$ in gonad-intact and gonadectomised animals in Experiments 1, 2 and 3

\begin{tabular}{|c|c|c|c|c|c|c|}
\hline & \multicolumn{6}{|c|}{ Pretreatment cortisol $(\mathrm{ng} / \mathrm{ml})$} \\
\hline & \multicolumn{2}{|c|}{ Experiment 1} & \multicolumn{2}{|c|}{ Experiment 2} & \multicolumn{2}{|l|}{ Experiment 3} \\
\hline & Saline day & ACTH day & Saline day & Insulin day & No-stress day & Stress day \\
\hline $\begin{array}{l}\text { gonad-intact } \\
\text { (males + females) }\end{array}$ & $6 \cdot 9 \pm 0 \cdot 9^{a}$ & $5 \cdot 7 \pm 1 \cdot 3^{a}$ & $4 \cdot 6 \pm 0 \cdot 7^{a}$ & $4 \cdot 0 \pm 0 \cdot 8^{a}$ & $5 \cdot 4 \pm 0 \cdot 5^{a}$ & $4 \cdot 9 \pm 0 \cdot 7^{\mathrm{a}}$ \\
\hline $\begin{array}{l}\text { gonadectomised } \\
\text { (males + females) }\end{array}$ & $11 \cdot 9 \pm 2 \cdot 3^{b}$ & $16 \cdot 9 \pm 7 \cdot 8^{b}$ & $7 \cdot 4 \pm 1 \cdot 1^{b}$ & $6 \cdot 9 \pm 1 \cdot 3^{b}$ & $3 \cdot 5 \pm 0 \cdot 4^{b}$ & $3 \cdot 2 \pm 0 \cdot 3^{b}$ \\
\hline
\end{tabular}

\footnotetext{
${ }^{a, b}$ Significant $(P<0.05)$ difference between gonad-intact and gonadectomised animals.
} 


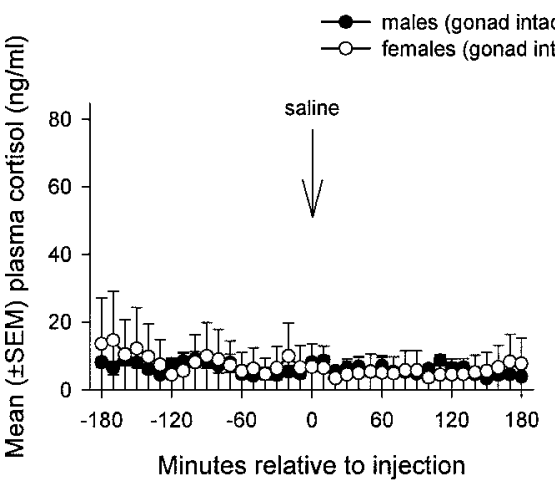

Figure 3 Mean ( \pm S.E.M.) plasma concentrations of cortisol in males (gonad intact+gonadectomised; 0 ) and females (gonad intact+gonadectomised; $\bigcirc$ ) for $180 \mathrm{~min}$ before to $180 \mathrm{~min}$ after intravenous injection of saline (left panel) and insulin (2 IU/kg live-weight; right panel). *Significant $(P<0 \cdot 05)$ difference between males and females. Significant changes over time are described in Results.

concentrations for the remainder of the sampling period. There were no significant changes in plasma concentrations of cortisol in response to injection of saline (Fig. 3).

From 50-120 min after injection of insulin, plasma concentrations of cortisol were significantly $(P<0 \cdot 05)$ higher in males (gonad intact+gonadectomised) than in females (gonad intact+gonadectomised; Fig. 3). Conversely, 150 and $170 \mathrm{~min}$ after injection of insulin, concentrations were higher $(P<0 \cdot 05)$ in females (gonad intact+gonadectomised) than males (gonad intact+ gonadectomised; Fig. 3). Gonadal status did not influence the increase in cortisol following injection of insulin, therefore, data from all males (gonad intact+ gonadectomised) and from all females (gonad intact + gonadectomised) were combined for presentation in Fig. 3 .

Gonadectomised animals (males+females) had significantly $(P<0 \cdot 05)$ higher pretreatment plasma concentrations of cortisol than those that were gonad intact (males+females; Table 1). Sex did not influence pretreatment concentrations of cortisol.

\section{Experiment 3-response to isolation/restraint stress}

Plasma concentrations of cortisol Across all groups (all groups combined), mean ( \pm S.E.M.) plasma concentrations of cortisol were significantly $(P<0 \cdot 05)$ higher than pretreatment concentrations from the onset of isolation/ restraint stress (Time $=0 \mathrm{~min}$ ) for the remainder of the sampling period (except in the 5th hour where concentrations were not significantly different to pretreatment concentrations; Fig. 4). There were no significant changes in plasma concentrations of cortisol on the control day of sampling in response to 'no-stress' (Fig. 4).

Plasma concentrations of cortisol were significantly higher $(P<0 \cdot 05)$ in females (gonad intact+gonadectomised) than males (gonad intact + gonadectomised) at the onset of isolation/restraint stress (Time $=0 \mathrm{~min}$ ), from $30-50 \mathrm{~min}$ after the onset of isolation/restraint stress and in the second, third and eighth hours of isolation/restraint stress (Fig. 4). Gonadal status did not influence the increase in cortisol following isolation/restraint stress, therefore data from all males (gonad intact+gonadectomised) and from all females (gonad intact+gonadectomised) were combined for presentation in Fig. 4.

Pretreatment plasma concentrations of cortisol were significantly $(P<0 \cdot 05)$ higher in gonad-intact (males+ females) than in gonadectomised (males+females) animals (Table 1). Sex did not influence pretreatment concentrations of cortisol.

There were fluctuations in the plasma concentrations of cortisol in the first $8 \mathrm{~h}$ of sampling across all groups and both days (all groups combined). Plasma concentrations of cortisol in the second and third hours of sampling were significantly $(P<0 \cdot 05)$ higher and those in the fifth to eighth hours of sampling were significantly $(P<0.05)$ lower than those in the first hour of sampling.

Plasma concentrations of $\mathbf{L H}$ In gonadectomised animals (males+females), mean plasma concentrations of LH were significantly $(P<0 \cdot 05)$ lower in the first $4 \mathrm{~h}$ of isolation/restraint stress compared with those in the $4 \mathrm{~h}$ immediately preceding stress (Fig. 5). In contrast, there was no such decrease in plasma LH in gonad-intact animals (males+females). Conversely, on the day of no stress, in the first $4 \mathrm{~h}$ of 'no-stress', mean plasma concentrations of LH in gonadectomised animals (males+females) were significantly $(P<0 \cdot 05)$ higher than in the preceding period. The equivalent change was not seen in gonad intact animals (males+females). Sex did not influence mean plasma concentrations of $\mathrm{LH}$, therefore data from all gonad intact animals (males+females) and from all 

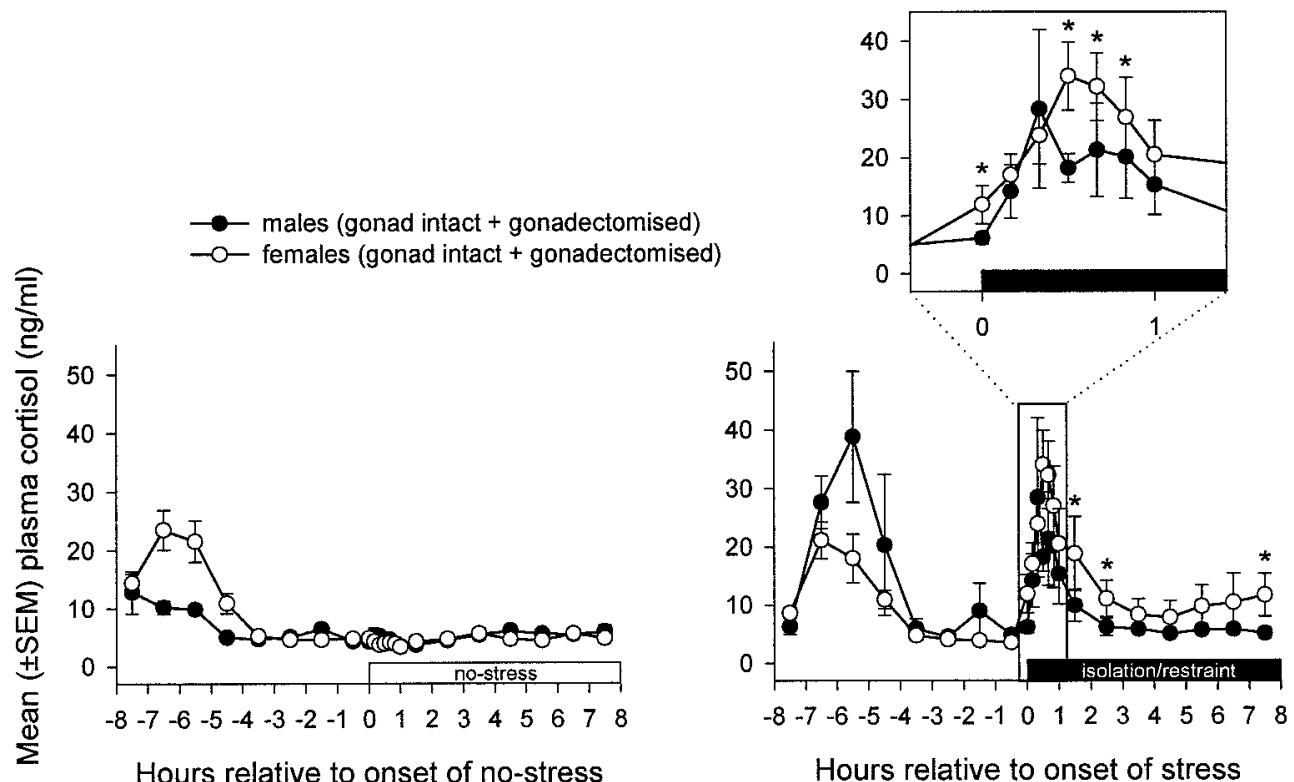

Hours relative to onset of stress

Figure 4 Mean ( \pm S.E.M.) plasma concentrations of cortisol in males (gonad intact+gonadectomised; 0 ) and females (gonad intact+gonadectomised; $\bigcirc$ ) for $8 \mathrm{~h}$ before and during $8 \mathrm{~h}$ where no stress was imposed (left panel), during $8 \mathrm{~h}$ where isolation/restraint stress was imposed (right panel) and, in detail, during the 1st hour of isolation/restraint stress (inset). *Significant $(P<0 \cdot 05)$ difference between males and females.

Significant changes over time are described in Results.

gonadectomised animals (males+females) were combined for presentation in Fig. 5.

Overall, the amplitude of LH pulses, the number of pulses per hour and the pre-LH pulse nadir were significantly $(P<0 \cdot 05)$ higher in gonadectomised animals (males+females; $1 \cdot 3 \pm 0 \cdot 1 \mathrm{ng} / \mathrm{ml}, 0 \cdot 45 \pm 0 \cdot 03$ pulses and $2 \cdot 7 \pm 0 \cdot 2 \mathrm{ng} / \mathrm{ml}$, respectively) than in gonad-intact animals (males+females; $0.5 \pm 0.1 \mathrm{ng} / \mathrm{ml}, \quad 0 \cdot 13 \pm 0.01$ pulses and $0 \cdot 8 \pm 0 \mathrm{ng} / \mathrm{ml}$, respectively). There were no significant changes in these parameters due to isolation/ restraint nor were there any significant differences between males and females.

When both days were considered together (all groups combined), mean plasma concentrations of LH were significantly $(P<0 \cdot 05)$ lower during the first $4 \mathrm{~h}$ of sampling than in the subsequent $4 \mathrm{~h}$ of sampling (Fig. 5). This effect was not reflected in any of the other parameters of $\mathrm{LH}$ secretion.

\section{Discussion}

Our results show that there are sex differences in the response of the hypothalamo-pituitary-adrenal axis to stress but this depends on the type of stressor. While males had a greater cortisol response to insulin-induced hypoglycaemia, females had a greater cortisol response to isolation/restraint stress. Our results also suggest that these sex differences in the response to stressors were likely to be due to differences in the secretion and/or actions of corticotrophin releasing factor (CRF) and/or AVP rather than to the responsiveness of the adrenal cortex to ACTH since there was no sex difference in the response of the adrenal gland to standard treatment with ACTH. Despite the greater increase in cortisol in females during isolation/ restraint stress, there were no differences between the sexes in the suppression of $\mathrm{LH}$ secretion due to this stress. If a major means by which stress causes a suppression of LH secretion involves glucocorticoids, it might have been expected that there would have been a difference between the sexes in the effect of isolation/restraint on LH secretion. Consequently, the lack of a sex difference in the suppression of $\mathrm{LH}$ during stress suggests that glucocorticoids may not be a major mediator of the stress-induced suppression of LH. This is consistent with the conclusions of Tilbrook et al. (1999) and studies conducted in other species (for review see Tilbrook et al. 2000).

Males and females responded differently to the various stressors. While males had a greater cortisol response to the metabolic stressor of insulin-induced hypoglycaemia, females had a greater cortisol response to the physical/psychological stressor of isolation/restraint. Previous studies have measured the cortisol response to insulin-induced hypoglycaemia in ewes (Engler et al. 1989, Canny et al. 1989, 1990) or rams (Caraty et al. 1990, Guillaume et al. 1992a, b) but none has conducted a systematic sex comparison as we have done here. The 
a) gonad intact (males + females)
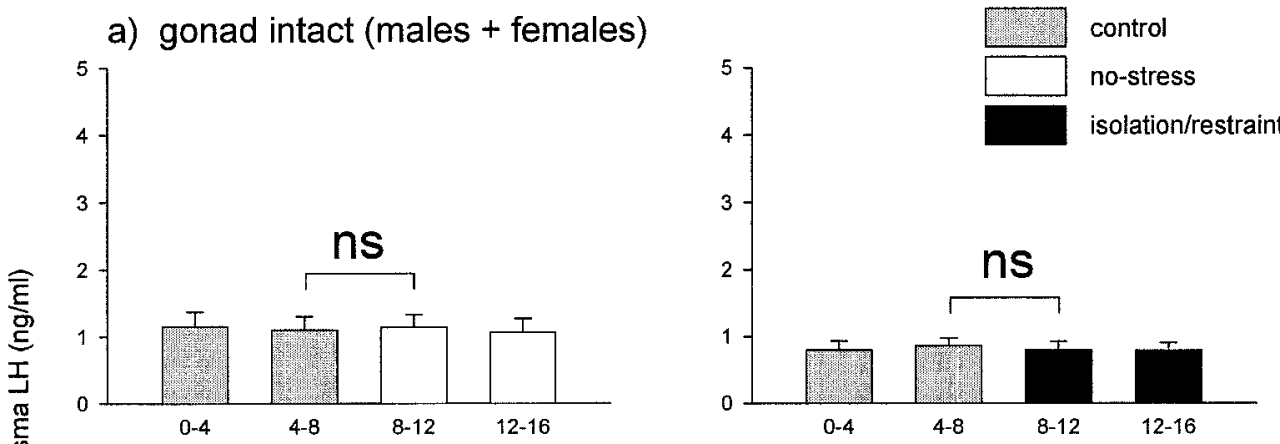

b) gonadectomised (males + females)
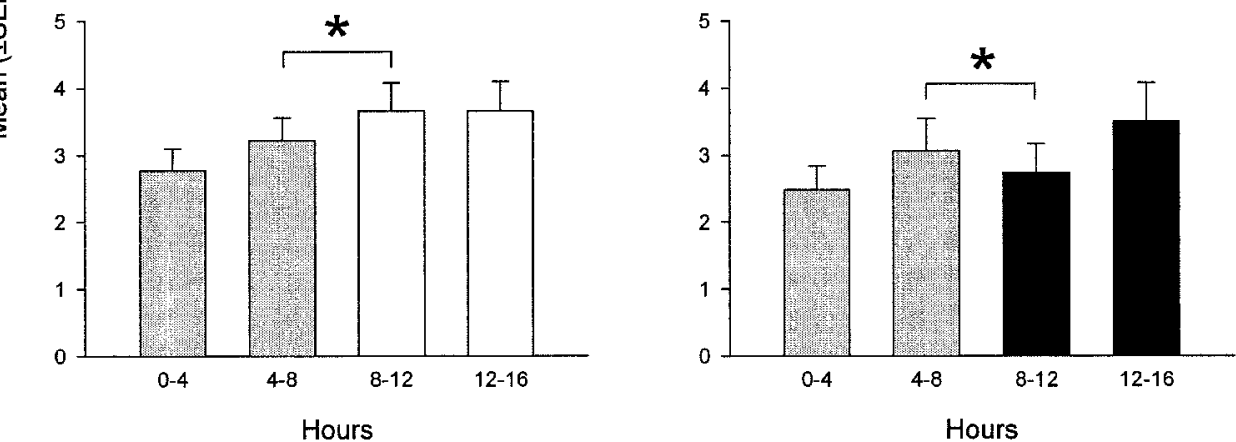

Figure 5 Mean ( \pm S.E.M.) plasma concentrations of LH for $4 \mathrm{~h}$ blocks in gonad-intact (males +females; a) and gonadectomised (males + females; b) animals for $8 \mathrm{~h}$ before and during $8 \mathrm{~h}$ where no stress was imposed (left panels) and during $8 \mathrm{~h}$ where isolation/restraint stress was imposed (right panels). 'ns' indicates that concentrations at $8-12 \mathrm{~h}$ were not significantly different to those at $4-8 \mathrm{~h}$. ${ }^{*}$ Mean concentrations of $\mathrm{LH}$ at $8-12 \mathrm{~h}$ were significantly $(P<0 \cdot 05)$ different to those at $4-8 \mathrm{~h}$.

precise mechanism by which insulin-induced hypoglycaemia activates the hypothalamo-pituitary-adrenal axis is unknown but previous studies have indicated that this stressor activates all levels of the axis. For instance, CRF and AVP in the hypophysial-portal circulation, and ACTH in the peripheral circulation, were elevated following injection of insulin in ewes (Engler et al. 1989, Canny et al. 1989) and rams (Caraty et al. 1990). Studies in rats suggest that the activation of the hypothalamopituitary-adrenal axis by insulin-induced hypoglycaemia may be mediated primarily by glucose-sensitive neurones in the hypothalamus (Aizawa et al. 1981, Widmaier et al. 1988). The observed $30 \mathrm{~min}$ delay between injection of insulin and a significant elevation of cortisol is consistent with results of previous studies (Engler et al. 1989, Canny et al. 1989, 1990; Guillaume et al. 1992a). Our earlier study that made a comparison between sexes in the cortisol response to isolation/restraint stress (Tilbrook et al. 1999) found no significant difference between gonadectomised rams and ewes. It is not clear why we found no sex difference in gonadectomised rams and ewes treated with gonadal steroids in our previous study and a sex difference in the current study where gonad intact animals were also included. It is possible that any sex differences in the cortisol response to stress are due to gonadal factors other than the sex steroids (Tilbrook et al. 1999) and this may explain the disparate findings in the different studies. Nevertheless, the current results demonstrate for the first time that the sex that has the greater cortisol response to a stressor depends on the type of stressor that is imposed. This has not previously been demonstrated in other species. Indeed, in rats, it appears to be well accepted that stress-induced concentrations of glucocorticoids are higher in females than in males in response to various stressors (Handa et al. 1994, Jezova et al. 1996). It is equally well recognised that organisms show different stress-responses to different stressors (Rivier \& Rivest 1991, Chrousos 1998, Tilbrook et al. 2000). Our results in sheep expand this notion to show that the response to specific stressors depends on sex.

The lack of a sex difference in the cortisol response to standard treatment with ACTH is surprising because the adrenal glands of ewes have been shown to be larger than those of rams (Canny et al. 1999). Furthermore, in vitro data have shown that ACTH-induced cortisol production was greater in cultures of ewe adrenocortical cells than in cultures of ram adrenocortical cells (Canny et al. 1999). Nevertheless, adrenocortical cells from males had higher 
basal secretion of cortisol than adrenocortical cells from females (Canny et al. 1999). Our findings contrast with studies in rodents that have shown that the corticosterone response to $\mathrm{ACTH}$ in females is greater than that of males (for review see Handa et al. 1994). Nevertheless, the lack of a sex difference at this level in sheep suggests that differences between the sexes in the cortisol response to stressors arise from differences at the level of the hypothalamo-pituitary unit rather than differences in the responsiveness of the adrenal gland to stimulation by ACTH. Differences between the sexes may exist in the secretion of CRF and/or AVP, and/or in the responsiveness of the corticotrophs of the anterior pituitary to these hypophysiotrophic hormones. Indeed, Canny et al. (1999) found that males had higher concentrations of AVP in the median eminence and higher concentrations of proopiomelanocortin in the anterior pituitary gland than females, and females had higher basal secretion of ACTH from cultured anterior pituitary cells than males.

Gonadal status, but not sex, influenced the impact of isolation/restraint stress on the secretion of LH with the secretion of LH being suppressed by isolation/restraint in gonadectomised animals (of both sexes) but not in those that were gonad intact. The lack of an effect of isolation/ restraint stress on the secretion of $\mathrm{LH}$ in gonad intact animals may simply be due to the naturally low secretion of LH that exists in intact Romney Marsh sheep at the stage of the breeding season at which the experiment was conducted (Bremner et al. 1984) potentially masking any differences. Alternatively, gonadal factors in gonad-intact animals may have interacted with the stress pathways activated during isolation/restraint to prevent the suppression of LH that was seen in gonadectomised animals. It is unusual to find changes in the mean plasma concentrations of LH that are not reflected in changes in some other parameter of LH secretion. Despite the lack of statistical differences in the frequency, amplitude and nadir of $\mathrm{LH}$ pulses in gonad-intact animals, it should be recognised that a meaningful statistical comparison of these parameters is not possible due to the low number of LH pulses in the intact animals. The low number of LH pulses found in gonad intact animals in this experiment is to be expected in this breed of sheep at this time of the year at our laboratory (Bremner et al. 1984).

It is not clear why animals that were gonadectomised had pretreatment concentrations of cortisol that were higher than those in gonad-intact animals in Experiments 1 and 2 but that were lower than those in gonad-intact animals in Experiment 3. This discrepancy between the experiments may be due to the amount of time between gonadectomy and the experimental procedures. It is not known whether gonadectomy influences the basal activity of the hypothalamo-pituitary-adrenal axis in sheep, but there is evidence that sex steroids can affect the activity of the hypothalamo-pituitary-adrenal axis in other species (Handa et al. 1994, Jezova et al. 1996). Caraty \& Locatelli
(1988) showed that basal activity of the hypothalamopituitary-testicular axis varied with time out of castration so it is feasible that the same could occur with other systems that are regulated by the hypothalamo-pituitary unit. Nevertheless, in a previous study where we had gonadectomised rams and ewes with and without sex steroid replacement, we found no difference in the pretreatment plasma concentrations of cortisol (Tilbrook et al. 1999). All of the animals used in our previous study were acutely gonadectomised so this issue is yet to be resolved.

In conclusion, we have demonstrated that male and female sheep differ in their cortisol response to different stressors and that the sex with the greater cortisol response is stressor specific. These sex differences appear to occur at the level of the hypothalamo-pituitary unit, as the cortisol response to standard treatment with ACTH did not differ between the sexes. Finally, while the secretion of LH was suppressed by isolation/restraint stress in gonadectomised animals, there was no such suppression in gonad intact animals and there was no sex difference. Given that there was a sex difference in the cortisol response to isolation/ restraint stress, this provides further support for the contention that the hypothalamo-pituitary-adrenal axis is not a major mediator of the stress-induced suppression of LH secretion.

\section{Acknowledgements}

We thank Bruce Doughton, Karen Briscoe, Alison Skinner, Michelle Ibbott, Tina Ambrose, Maree Purdon, Maurice Miles and Terry Squires for technical assistance. We also thank the late Ron Parr for his help and advice in these studies. This research was funded by the National Health and Medical Research Council of Australia and Monash University.

\section{References}

Aizawa T, Yasuda N \& Greer MA 1981 Hypoglycemia stimulates ACTH secretion through a direct effect on the basal hypothalamus. Metabolism: Clinical \& Experimental 30 996-1000.

Bocking AD, McMillen IC, Harding R \& Thorburn GD 1986 Effect of reduced uterine blood flow on fetal and maternal cortisol. Journal of Developmental Physiology 8 237-245.

Bremner WJ, Cumming IA, Winfield CG, De Kretser DM \& Galloway DB 1984 A study of the reproductive performance of mature Romney and Merino rams throughout the year. In Reproduction in Sheep, edn 1, pp 16-17. Eds DR Lindsay \& DT Pearce. Canberra: Australian Academy of Science and Australian Wool Corporation.

Canny BJ, Funder JW \& Clarke IJ 1989 Glucocorticoids regulate ovine hypophysial portal levels of corticotropin-releasing factor and arginine vasopressin in a stress-specific manner. Endocrinology 125 2532-2539.

Canny BJ, Clarke IJ \& Funder JW 1990 Adrenocorticotropin responses to endogenous and exogenous secretagogues in the sheep: specificity of glucocorticoid action. Neuroendocrinology 51 181-189. 
Canny BJ, O'Farrell KA, Clarke IJ \& Tilbrook AJ 1999 The influence of sex and gonadectomy on the hypothalamo-pituitary-adrenal axis of the sheep. Journal of Endocrinology 162 215-225.

Caraty A \& Locatelli A 1988 Effect of time after castration on secretion of LHRH and LH in the ram. Journal of Reproduction and Fertility 82 263-269.

Caraty A, Grino M, Locatelli A, Guillaume V, Boudouresque F, Conte-Devolx B \& Oliver C 1990 Insulin-induced hypoglycemia stimulates corticotropin-releasing factor and arginine vasopressin secretion into hypophysial portal blood of conscious, unrestrained rams. The Journal of Clinical Investigation 85 1716-1721.

Chrousos GP 1998 Stressors, stress, and neuroendocrine integration of the adaptive response. The 1997 Hans Selye Memorial Lecture. Annals of the New York Academy of Sciences 851 311-335.

Da Silva JA 1995 Sex hormones, glucocorticoids and autoimmunity: facts and hypotheses. Annals of the Rheumatic Diseases 54 6-16.

Dobson H \& Smith RF 1995 Stress and reproduction in farm animals. Journal of Reproduction and Fertility Supplement 49 451-461.

Engler D, Pham T, Fullerton MJ, Ooi G, Funder JW \& Clarke IJ 1989 Studies of the secretion of corticotropin-releasing factor and arginine vasopressin into the hypophysial-portal circulation of the conscious sheep 1. Effect of an audiovisual stimulus and insulin-induced hypoglycemia. Neuroendocrinology 49 367-381.

Geschwind II \& Dewey R 1968 Dynamics of luteinizing hormone (LH) secretion in the cycling ewe: a radioimmunoassay study. Proceedings of the Society for Experimental Biology and Medicine 129 451-455.

Guillaume V, Conte-Devolx B, Magnan E, Boudouresque F, Grino M, Cataldi M, Muret L, Priou A, Deprez P, Figaroli JC \& Oliver C $1992 a$ Effect of chronic active immunization anti-corticotropinreleasing factor on the pituitary-adrenal function in the sheep. Endocrinology $1302291-2298$.

Guillaume V, Conte-Devolx B, Magnan E, Boudouresque F, Grino M, Cataldi M, Muret L, Priou A, Figaroli JC \& Oliver C $1992 b$ Effect of chronic active immunization with antiarginine vasopressin on pituitary-adrenal function in sheep. Endocrinology $\mathbf{1 3 0}$ 3007-3014.

Handa RJ, Burgess LH, Kerr JE \& O’Keefe JA 1994 Gonadal steroid hormone receptors and sex differences in the hypothalamopituitary-adrenal axis. Hormones and Behavior 28 464-476.

Jezova D, Jurankova E, Mosnarova A, Kriska M \& Skultetyova I 1996 Neuroendocrine response during stress with relation to gender differences. Acta Neurobiologiae Experimentalis 56 779-785.

Karsch FJ, Cummins JT, Thomas GB \& Clarke IJ 1987 Steroid feedback inhibition of pulsatile secretion of gonadotropin-releasing hormone in the ewe. Biology of Reproduction 36 1207-1218.
Kitay JI 1961 Sex differences in adrenal cortical secretion in the rat. Endocrinology 68 818-824.

Lee VWK, Cumming IA, De Kretser DM, Findlay JK, Hudson B \& Keogh EJ 1976 Regulation of gonadotrophin secretion in rams from birth to sexual maturity I. Plasma LH, FSH and testosterone levels. Journal of Reproduction and Fertility 46 1-6.

Moberg GP 1985 Biological response to stress: key to assessment of animal well-being? In Animal Stress, pp 27-49. Ed. GP Moberg. Baltimore: Williams \& Wilkins.

Moberg GP 1987 Influence of the adrenal axis upon the gonads. In Oxford Reviews of Reproductive Biology, pp 456-496. Ed. JR Clarke. Oxford: Clarendon Press.

Parr RA, Davis IF, Fairclough RJ \& Miles MA 1987 Overfeeding during early pregnancy reduces peripheral progesterone concentration and pregnancy rate in sheep. Journal of Reproduction and Fertility 80 317-320.

Patchev VK \& Almeida OF 1998 Gender specificity in the neural regulation of the response to stress: new leads from classical paradigms. Molecular Neurobiology 16 63-77.

Radford HM, Watson RH \& Wood GE 1960 A crayon and associated harness for the detection of mating under field conditions. Australian Veterinary Journal 36 57-66.

Rivier C \& Rivest S 1991 Effect of stress on the activity of the hypothalamic-pituitary-gonadal axis: peripheral and central mechanisms. Biology of Reproduction 45 523-532.

Thorburn GD, Bassett JM \& Smith ID 1969 Progesterone concentration in the peripheral plasma of sheep during the oestrous cycle. Journal of Endocrinology 45 459-469.

Tilbrook AJ, Canny BJ, Serapiglia MD, Ambrose TJ \& Clarke IJ 1999 Suppression of the secretion of luteinizing hormone due to isolation/restraint stress in gonadectomized rams and ewes is influenced by sex steroids. Journal of Endocrinology 160 469-481.

Tilbrook AJ, Turner AI \& Clarke IJ 2000 Effects of stress on reproduction in non-rodent mammals: considerations of the role of glucocorticoids and sex differences. Reviews of Reproduction $\mathbf{5}$ 105-113.

Widmaier EP, Plotsky PM, Sutton SW \& Vale WW 1988 Regulation of corticotropin-releasing factor secretion in vitro by glucose. American Journal of Physiology 255 E287-E292.

Young EA 1995 The role of gonadal steroids in hypothalamicpituitary-adrenal axis regulation. Critical Reviews in Neurobiology 9 371-381.

Received 20 November 2001

Accepted 19 December 2001 